\title{
ETIKA SEBAGAI DASAR PENGENDALIAN DIRI MANUSIA
}

\author{
Oleh \\ I Nyoman Subagia \\ Dosen pada Fakultas Dharma Acarya IHDN Denpasar
}

\begin{abstract}
Men are full of desires that need to be satisfied through functioning the senses, which are part of the mind used for reasoning, feeling, and acting. From the senses happiness or sadness may come. When the senses are connected to the out world the selves within may see problems even calamities if the desires are uncontrolled. In Hindu there are several teachings that can be refered to as the ethics for controlling the self. Trikaya Parisudha teaches that life should be directed to reach happiness by thinking, speaking, and doing good. The Sad Ripu teaches the six enemies within self that are to fight, namely desires, greediness, anger, disorientation, drunkness, and envy. Sapta Timira teaches seven things that can blind the mind, namely beauty, rich, intellectuality, family line, youth, alchoholic beverage, braveness. Beisdes all of them, the inclination of being good or bad that are latent within the self should be also realized as Hindus.
\end{abstract}

\section{Key Words: Ethics, Self-Control}

\section{PENDAHULUAN}

Manusia adalah homo sosius makhluk berteman.Ia tidak dapat hidup sendirian, ia selalu bersama sama dengan orang lain. Manusia hanya dapat hidup dengan sebaik- baiknya dan manusia hanya akan mempunyai arti, apabila ia hidup bersamasama dengan manusia lainnya di dalam masyarakat. Tidak dapat dibayangkan adanya manusia yang hidup menyendiri tampa berhubungan dan tampa bergaul dengan sesama manusia lainnya. Hanya dalam hidup bersama manusia akan dapat berkembang dengan wajar. Hal ini ternyata bahwa sejak lahir sampai meninggal manusia memerlukan bantuan orang lain, untuk kesempurnaan hidupnya. Bantuan ini tidak hanya bantuan untuk memenuhi kebutuhan jasmani tetapi juga untuk kebutuhan rohani. Manusia sangat memerlukan pengertian, kasih sayang, harga diri, pengakuan,dan tanggapantanggapan emosional yang sangat penting artinya bagi pergaulan dan kelangsungan hidup yang sehat.

Semua kebutuhan ini merupakan kebutuhan rohani hanya dapat ia peroleh dalam hubungannya dengan manusia lain dalam masyarakat. Inilah kodrat manusia sebagai makhluk sosial. Tidak ada seorangpun yang dapat mengingkari hal ini karena ternyata bahwa manusia baru dapat disebut manusia dalam hubungananya dengan orang lain, bukan dalam kesendiriannya. Dalam kehidupan bersama ini orang harus mengatur dirinya dalam bertingkah laku. Tak ada seorangpun boleh berbuat sekehendak hatinya. Ia harus menyesuaikan dirinya dengan lingkungan, tunduk kepada aturan bertingkah laku yang berlaku. Dengan demikian maka orang hanya bebas berbuat dalam ikatan haturan tingkah laku yang baik. Peraturan untuk bertingkah laku yang baik disebut orang tata susila. Nama lainnya adalah etika. Bila etikad beretika masih dalam angan disebut orang budi yang baik dan bila diwujudkan dalam tindakan disebut budi pakerti yang baik. Dalam tujuan etika ini maka orang dinilai dari tingkah laku, mana yang dapat dinilai baik dan mana yang jahat.

\section{II.PEMBAHASAN \\ 2.1 Pengendalian diri}

Agar manusia tidak dikuasi oleh kecendrungankecendrungan yang rendah ia harus mengendalikan diri dari guncangan-guncangan hati yang tidak baik. Guncangan- guncangan itu semula ada dalam angan dalam bentuk keinginan. Dengan kemampuan berwiweka maka manusia dapat memilih yang baik yang benar dan menghindarkan diri dari yang buruk dan salah dalam memenuhi segala keinginannya.

Setiap keinginan menuntut kepuasan pada obyeknya. Indria merupakan alat untuk memenuhi keinginan itu. Indrialah yang mengubungkan manusia dengan alam ini. Sentuhan indria dengan alam ini menimbulkan guncangan-guncangan pribadi manusia. Bahkan tidak jarang manusia mendapatkan celaka kerena terlalu memenhi keinginan indrianya. Karena itu orang harus dapat mengendalikan indria pada hal-hal yang membawa pada kerahayuan. Kitab Sarasamuscaya sloka 71 mengatakan demikian : 
Indriyâòyayeva tat sarvam yat

Svarga narakâvubhau,

Nig ${ }^{\circ}$ hitanis ${ }^{\text {ooo }}$ tâni svargaya narakâca

$y a$.

Terjemahannya:

Inilah yang patut saya ajarkan lagi, Inrialah yang dianggap penyebab sorga dan naraka, bila orang sanggup mengendalikannya, itu semata-mata sorga namanya, tetapi bila tidak sanggup mengendalikannya benar-benar narakalah ia. ( Kajeng,1999:60).

Kitab katha Upanisad I . 3 menyebutkan demikian:

Âtmanah rathinam viddhi,

Úarîram ratham eva tu,

Buddhim tu sarathim viddhi.

Manah pragraham eva ca.

Terjemahannya :

Katahuilah bahva sang pribadi adalah Tuanya kereta, badan adalah kereta Ketahuilah bahwa kebijaksanaan itu adalah kusir dan pikiran adalah tali kekangnya. (Sura, $1991 ; 36$ ).

Indria adalah kuda, sasaran indria adalah jalan sang atma dihubungkan dengan badan, indria dan pikiran adalah menikmati. Dia yang memiliki kesadaran, yang pikirannya selalu terkendali, yang indrianya dapat diawasi semua itu laksana kuda yang bagus bagi si kusir. Tetapi ia yang tidak memiliki kesadaran, yang tidak kuasa atas pikirannya yang tidak suci, ia tidak akan sampai pada tujuan hidupnya bahkan akan kembali pada kesengsaraan. Ia yang memiliki kesadaran yang kuasa atas pikirannya yang senantiasa suci bersih, akan mencapai tujuan hidupnya dan karena itu tidak akan dilahirkan ke dunia ini lagi. Ia yang memiliki kesadaran akan kusir kereta itu dan dapat mengendalikan tali kekang pikirannya, ia akan mencapai akhir dari perjalannya itu yaitu alam tertinggi alamnya ia mencapai segalanya.

\subsection{Pengertian Etika}

Etika adalah pengetahuan tentang kesusilaan. Kesusilaan berbentuk kaidah -kaidah yqng berisi larangan-larangan atau suruhan - suruhan untuk berbuat sesuatu. Dengan demikian dalam etika, kita akan dapati ajaran tentang perbuatan yang baik dan perbuatan yanag buruk. Perbuatan yang baik itulah supaya dilaksanakan dan perbuatan yang buruk itu harus dihindari.

Tiap-tiap perbuatan itu berdasarkan atas kehendak atau budhi. Jadi apa yang diperbuatan orang itu bermula dari kehendak. Oleh karena manusia dihadapkan kepada dua pilihan yaitu pilihan kepada yang baik dan yang buruk maka ia harus mempunyai kehendak bebas untuk memilih. Tampa kebebasan itu orang tidak dapat memilih yang baik.Namun bebaskah manusia sebebas-bebasnya mrmilih menurut kehendaknya ? Dalam hubungan ini manusia mempunyai kebebasan yang terbatas juga. Yang membatasinya itu adalah aturan-aturan atau norma-norma yang berlaku.

Pada mulanya norma berarti penyiku, suatu perkakas yang digunakan oleh tukang kayu untuk mengetahui apakah suatu sudut memang benarbenar siku-siku. Bahkan pembuat perabot rumah tidak akan secara untung-untungan menggergaji sebilah papan, sebelum ia menggambarkan sebuah sudutsiku-siku pada papan tersebut. Dengan demikian norma berarti sebuah ukuran yang kemudian dalam hubungan dengan etika berarti pedoman, ukuran atau haluan untuk bertingkah laku. Norma ini timbul karena kita berada bersama orang lain dan lingkungan hidup dan alam.

Etika dalam agaama Hindu adalah tentu norma agama Hindu yang dijadikan titik tolak berpikir. Demikian pula pola-pola kepercayaan, paham-paham filsafat agama Hindu mempunyai kedudukan yang amat penting dalam etika Hindu. Kepercayaan agama Hindu berpangkal dari kepercayaan kepada hyang Widhi yang berada di mana-mana, yang mengetahui segalanya. Beliau adalah saksi agung yang menjadi saksi segala perbuatan manusia. Karena itu manusia tidak dapat menyembunyikan segala perbuatannya terhadap Hyang Widhi baik perbuatan itu perbuatan yang baik maupun yang buruk. Dalam Atharva Veda 11.16.2. disebutkan sebagai berikut:

Yas tiûphati carati yaceca vañcati yo nilâyam carati yah pratañkam dvau sanniûadya yamantrayete râjâ tad veda varuóas tåtiyah.

Terjemahannya:

Siapapun berdiri, berjalan ,bergerak dengan senbunyi-sembunyi, siapaun yang membaringkan diri atau bangun, ataupun dua orang yang duduk bersama bisikan satu dengan yang lainnya, semua itu Tuhan, Sang Raja mengetahui, Ia adalah yang ketiga hadir disana.(Sura,1991;33).

Selanjutnya dalam Adiparwa I.36 disebutkan sebagai berikut :

Aditya Sanhyang Sûrya Candra Sanghyang Wulan, Anilânala Sanghyang Angin muang apuy. Tumût ta Sanghyang Âkaúa Prçthiwi muang Toya, muwah Sanghyang Âtma, Sanghyang Yama tamolah ring rât kabeh. 
Nâhan tang rahina wçngi muang sandhyâ, lawan Sanghyang Dharma sira, sang dewata mangkana tiga wçlas kwehnira, sira ta mengaweruhi ulahning wwang ring jagat Tan kçna byâpâra nireng rât.

Terjemahannya:

Matahari, Bulan, Angin dan Api.Bumi dan Air, Hyang Âtma, Hyang Yama yang berada di seluruh dunia. Demikian pula siang, malam dan sandhyakala dengan Hyang Dharma. Para Dewa itu tiga belas banyaknya. Semua itu tahu akan tingkah laku orang di seluruh dunia. Tidak dapat diklabui Dewa itu memenuhi dunia.(Sura,1991;34)

Disamping keyakinan bahwa Hyang Widhi mengetahui semua perbuatan orang, umat Hindu amat meyakini adanya hukum karma yang menyatakan bahwa setiap perbuatan itu ada akibatnya. Bila seseorang berbuat baik maka ia akan memetik buah yang baik dan bila seseorang berbuat buruk maka ia akan memetik buah yang buruk.Seperti disebutkan oleh kutipan pustaka di bawah ini :

Syapa kari tan temuñ hayu masâdhana sarvva hayu,

Niyata katçmwaniñ hala masâdhana sarvva hala,

Tewasalisuh manañsaya purâkrta tâpa tinût, Sakaharepan kasiddha maka daroana Pandhusuta.

Terjemahannya :

Siapapun akan mendapatkan kebahagiaan apabila melakukan perbuatan yang baik, pasti penderitaan yang akan dijumpai, apabila melakukan berbuatan yang buruk, mendapatkan keburukan orang yang tidak percaya hasil perbuatan dahulu, supaya segala tujuan bisa tercapai sebagai contoh Sang Arjuna. (Kakawin Arjuna Wiwaha, 1988;42).

Selanjutnya dalam Sarasamuccaya sloka 21 menyebutkan sebagai berikut :

Surûpa tâm âtma gumam ca vistaram

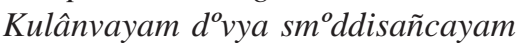

Naro hi sarvam labhate yathâk ${ }^{\circ}$ tam

Sadâúubhenâtmak tenakarmanâ.

Terjemahannya :

Maka orang yang melakukan perbuatan baik, kelahirnan nya dari sorga kelak menjadi orang yang rupawan, gunawan, muliawan, hartawanm dan berkekuasaan, buah hasil perbuatan yang baik, didapat olehnya. (Kajeng,1999;20 ).

Keyakinan akan adanya Hyang Widhi yang mengetahui segala dan adanya hukum karma menyusup sampai ke lubuk hati umat Hindu sehingga mereka berusaha menghindari perbuatan-perbuatan jahat yang amat tercela itu. Oleh karena etika agama Hindu bertolak dari norma agama maka ia tidak sekedar etika penampilan luar ebagai etiket saja namun ia menuntun orang untuk berbudi pekerti yang luhur. Persoalan-persoalan yang diajarkannya pun juga tentang perbuatan baik dan buruk, salah dan benar. Untuk dapat memilih yang baik, yang benar orang menggunakan wiwekanya yaitu kemampuannya untuk membeda-bedakan, memilih dua hal yang berbeda yang kemampuannya itu merupakan pembawaan lahir.

\subsection{Indriya}

Indriya adalah merupakan bagian dari alam pikiran kita untuk mengenal, merasakan dan melaksanakan sesuatu. Dari indriya inilah timbulnya keinginan-keinginan dan melalui indriya pula kita mendapatkan kepuasan, kesenangan atau kesusahan. Dalam diri manusia ada sebelas indriya yang disebut sebagai ekadasendriya. Pikiran adalah raja dari indriya (rajendriya) dan sisanya dasendriya adalah sepuluh indriya yang ada pada diri kita. Sepuluh indriya tersebut dapat dibedakan menjadi dua macam yaitu : panca buddhindriya dan panca karmendriya.

Panca Buddhindriya ialah : lima indriya penyebab yang menyebabkan orang dapat mengetahui dan merasakan sesuatu, kelima indriya tersebut ialah :

1. Cakswindriya, ialah indriya yang menyebabkan orang dapat melihat, terletak di mata.

2. Crotendriya, ialah indriya yang menyebabkan orang dapat mendengar melaui telinga.

3. Granendriya, ialah indriya yang menyebabkan orang dapat membau melaui hidung.

4. Jihwendriya, ialah indriya yang menyebabkan orang yang dapat mengecap sesuatu melaui lidah.

5. Twakindriya, ialah indriya yang menyebabkan orang dapat merasakan rasa sentuhan, panas, dingin, melaui kulit.

Selanjutnya Panca Karmendriya, ialah lima indriya gerak/pekerja :

1. Panindriya, ialah indriya pekerja dengan tangan.

2. Padendriya, ialah indriya pekerja dengan kaki.

3. Garbhendriya, ialah indriya pekerja dengan perut.

4. Paywindriya, ialah indriya pekerja dengan pelepasan.

5. Upasthendriya, ialah indriya pekerja dengan kelamin laki-laki. 
Bhagendriya, ialah indriya pekerja dengan kelamin wanita.

Berhubung keinginan itu timbul dari indriya, maka indriya tersebut patut dikendalikan baik-baik sebab ia akan mengantarkan kita kepada kebahagiaan atau kesengsaraan, tetapi bukan bertarti kita harus mengekang segala apa yang timbul dari indriya tersebut. Kita patut mempertimbangkan keinginan indriya tersebut baik-baik agar supaya kita mendapatkan keselamatan di dalam hidup kita ini. Janganlah sampai kita diperbudak oleh indriya kita, tetapi kitalah harus memperbudaknya. Mahakala kita sampai diperbudak, payahlah keadaan diri kita dan kesengsaraanlah yang akan kita jumpai. Tetapi hendaklah disadari bahwa membunuh keinginankeinginan indriya itu sama sekali tidaklah benar, karena tuhan memberikan kita indriya adalah untuk kesempurnaan hidup kita. Hanya saja kita harus tahu mempergunakan dan tahu mengendalikannya agar supaya kita mendapatkan keselamatan. Dalam Sarasamuccaya sloka 71 disebutkan sebagai berikut ini.

Indriyàóyeva tat sarvam yat svarganarakàvubhau,

nirgåhitanisûâûtàni svargaya narakàya ca.

Nyang pajara waneh, indriya ikang sinanggah swarga naraka, kramanya, yan kawaûa kahåtanya, ya ika sàkûàt swarga ngaranya, yapwan tan kawâ̂a kahåtanya, sàkûàt naraka ika.

Terjemahannya :

Inilah yang patut (saya) ajarkan lagi, indriyalah yang dianggap sorga neraka, penjelasannya, bila sanggup mengendalikannya, itu sematamata sorgalah namanya, tetapi bila tidak sanggup mengendalikannya, benar-benar nerakalah ia itu (Kajeng,1999:60)

\subsection{Tri Kàyaparisudha}

Trikaya parisudha artinya tiga prilaku yang harus disucikan, yang meliputi: (1) Kayika: perilaku yang berhubungan dengan badan atau perbuatan; (2) Wacika : perilaku yang berhubungan dengan kata-kata; dan (3) Manacika : perilaku yang berhubungan dengan pikiran. Dalam gaguritan pupuh sinom disebutkan sebagai berikut ini :

Tri kaya-parisudha, tingkahe tatelu jati,

wetu saking budi satwa, wasanane ngawe becik,

kayika laksana luwih, wacika bebawos sadhu,

Manacika kanirmalan, kayun suci jati ening, nyandang tuju, angen ngemban Sang Hyang Âtma
Terjemahannya :

Tri kayaparisudha, adalah tiga prilaku yang utama, yang keluar dari budhi pekerti yang luhur, yang menyebabkan menjadi berperilaku yang baik, kayika parisudha adalah perbuatan yang baik, wacika parisudha adalah perkataan yang baik, manacika parisudha adalah pikiran yang suci tanpa noda, pikiran yang jernih dan suci, patut itu menjadi tujuan, dipakai untuk mengemban dan menyucikan Jiwa kita (Surada,2006:223).

\section{1) Kayika Pariúudha}

Kayika ialah segala prilaku yang berhubungan dengan badan. Bilamana perbuatan itu perbuatanyang benar dan baik maka disebut orang perbuatan itu kayika paricuddha. Setiap orang, selama hayat dikandung badan, selama itu ia harus berbuat sesuatu. Hidup adalah untuk berbuat. Tanpa berbuat sesuatu hidup didunia ini akan sia-sia belaka. Dengan berbuat, kita akan membuat suatu karma, yang akan menentukan kehidupan kita pada masamasa yang akan dating, haruslah pada waktu sekarang ini kita berbuat yang baik dan benar, sebab hanya perbuatan yang demikianlah akan mengantar kita kepada keselamatan masa dating. Banyaklah ada tindakan-tindakan yang berhubungan dengan badan yang patut kita cegah adanya. Kitab Saramuccaya sloka 76 menyebutkan sebagai berikut ini:

Pràóàtipatam stainyam ca, paradàrànathàpi và

trini pàpàni kàyena, sarvatah parivarjavet. Nihan yang tan ulahakena, syamàti màti, mangahal-ahal, si paradara, nahan tang telu tan ulahakena ring asing ring paribhàsa, ring àpatkàla, ring pangipyan tuwi singgahana juga.

Terjemahan :

Inilah yan gtidak patut dilaksanakan/dilakukan: membunuh, mencuri, berbuat zina; ketiganya itu janganlqah hendaknya dilakukan terhadap siapapun, baik secar berolok-olok, dalam keadaan dirundung malang, dalam khayalan sekalipun, hendaklah dihindari semuanya itu (Kajeng, 1999:63).

Itulah perbuatan yang patut diindari, tentu saja tidak hanya yang disebut diatas itu saja yang harus tidak dikerjakan, tetapi banyak lagi macamnya. Menyebut satu persatu tentu tidak mungkin.

\section{2) Wacika Pariúudha}

Wacika ialah segala prilaku yang berhubungan dengan kata-kata. Wacika paricuddha berarti berkata 
yang benar dan baik. Perkataan itu merupakan alan yang amat penting bagi kita, guna menyampaikan isi hati kita kepada orang lain. Dari kata-kata itu kita dapat menduga dan mengetahui isi hati seseorang, pun pula dengan kata-kata kita mendapatkan bermacam-macam pengetahuan.

Dengan kata-kata orang memberikan orang lain hiburan, namun karena kata-kata pula orang dapat menyusahkan dirinya sendiri dan orang lain. Katakata itu memegang peranan penting dalam menentukan selamat dan celakanya kehidupan orang. Dalam Niti Úàûtra disebutkan sebagai berikut ini.

Wasita nimittanta manemu laksmi,

wasita nimittanta pati kapangguh, wasita nimittanta manemu duhka, wasita nimittanta manemu mitra.

Terjemahan :

Karena perkataan engkau akan mendapatkan bahagia,

karena perkataan engkau akan menemui ajal, karena perkataan engkau akan mendapat kesusahan ,

karena perkataan engkau akan mendapat sahabat.

Demikian pentingnya perkataan itu dalam kehidupan kita, maka kita harus mengendalikan diri pada waktu berkata-kata agar supaya kata-kata kita itu adalah kata-kata yang benar dan berguna untuk kehidupan kita. Seringkali orang-orang tidak sadar akan dirinya, sehingga terhamburlah dari mulutnya kata-kata yang tidak patut diucapkan yang membawa kerugian kepada dirinyasendiri dan kepada orang lain. Oleh karena itu kesadaran akan diri dan ketenangan hati adalah factor yang penting benar pada waktu kita berbicara, lebih-lebih pula dalam membicarakan hal-hal yang penting-penting. Hendaknya orang sadar, bahwa kata-kata itu mempunyai kekuatan yang luar biasa hebatnya yang dapat mempengaruhi, merusak meresap kedalam hati sanubari orang.

Kata-kata itu dapat merupakan tirtha amerta yang sejuk nyaman, namun ia dapat pula merupakan racun yang menghancurkan, merusak jiwa dan raga manusia. Dalam Sarasamuccaya sloka 120 disebutkan sebagai berikut ini.

Vàkûàyakà vadanànniûpatanti yairàhatah ûocati ratryahàni,

parasya và marmasu te patanti tasmàddhiro nàvasåjet parê̂u.

Ikang ujar ahala - tan pahi lawan hru, songkabnya sakatempuhan denya juga alara, rêsêp ri hati, tatan keneng pangan turu ring rahina wengi ikang wang denya, matangnyan tan inujaraken ika de sang dhira purusa, sang ahning maneb manah nira.

Terjemahan :

Perkataan yang mengandung maksud jahat tiada beda dengan anak panah, yang dilepaskan; setiap orang ditempuhnya merasa sakit; perkataan itu meresap kedalam hati, sehingga menyebabkan tidak bisa makan dan tidur pada siang dan malam hari, oleh sebab itu tidak diucapkan perkataan itu oleh orang yang budiman dan wira-perkasa, pun oleh orang tetap suci hatinya (Kajeng, 1999:100).

\section{3) Manacika Pariúudha}

Manacika artinya : segala prilaku yang berhubungan dengan pikiran. Manacika pariccudha ialah : berpikir yang benar dan suci. Di antara tri kayaparicuddha itu pikiranlah yang memegang peranan yang terpenting. Apa yang dikatakan dan apa yang dilakukan orang, semuanya berasal dari pikirannya. Pikiran menjadi sumber segala apa yang dilakukan orang dan oleh kerena itu apabila pikirannya itu baik maka segala perbuatannya akan baik pula. Ajaran agama senantiasa memberikan nasehat agar supaya kita dapat mngendalikan pikiran kita. Lebih-lebih ajaran yoga amat mengutamakan pengendalian pikiran itu. Namun mngendalikan pikiran itu tidaklah mudah, sebab ia amat lincah, suka bertamasya kesana kemari, dan amat cepat pula perginya. Dalam Sarasamuccaya sloka 81 disebutkan sebagai berikut ini.

Dùagam bahudhàgmi pràrthanàsamcayàtmakam,

manah suniyatam yasya sa sukhi pretya veha ca.

Nihan ta kramanikang manah, bharanta lungha swabhàwanya, akweh inangênangênya, dadi pràrthana, dadi sangcaya, pinakawaknya, hana pwa wang ikang wenang humrt manah, sira tika manggêh amanggih sukha, mangke ring paraloka waneh.

Terjemahan :

Keadaan pikiran itu demikianlah : tidak berketentuan jalannya, banyak yang dicitacitakan, terhadang berkeinginan terkadang penuh kesangsian; demikianlah kenyataannya; jika ada orang yang dapat mengendalikan pikiran pasti orang itu memperoleh kebahagiaan, baik sekarang maupun didunia lain (Kajeng, 1999:67). 
Dengan kemauan yang tetap dan usaha yang terus dan teratur besar benar kemungkinannya kita akan dapat mengendalikan pikiran kita. Demikianlah juga mengendalikan indriya, bersumber pada pengendalian pikiran, karena alam pikiranlah asalnya indriya itu. Dalam Sarasamuccaya sloka 80 disebutkan sebagai berikut ini.

Mano hi mùlan sarvesàmindrayànam pravartate,

chubhàúubhasvavasthàsu Kàryam tat suvyavasthitam.

Apan ikang manah ngaranya, ya ika witning indriya, maprawrtti ta ya ring cubhacubhakarma, matangnyan ikang manah juga prihen kahrtanya sakareng.

Terjemahan :

Sebab yang disebut pikiran itu, adalah sumbernya nafsu, ialah yang mengerakkan perbuatan baik ataupun yang buruk; oleh karena itu, pikiranlah yang segera patut diusahakan pengekangannya/pengendaliannya (Kajeng, 1999:66-67).

Supaya kita bisa berpikir yang benar dan suci maka : jangan iri akan milik dan keberuntungan orang lain, jangan marah atau benci kepada semua mahluk dan tidak mengingkari akan kebenaran hukum karmaphala. Demikian ajaran kitab Saramusccaya tentang ajaran Trikàya pariúudha sebagai ajaran untuk mengendalikan indriya.

\subsection{Sad Ripu}

Sad Ripu artinya enam musuh. Enam musuh iu ialah (1) Kama artinya hawa nafsu; (2) Lobha artinya loba; (3) Krodha artinya kemarahan; (4) Moha artinya kebingungan; (5) Mada artinya kemabukan; (6) Matsarya artinya iri hati. Sad ripu terdapat pada setiap orang, hanya saja dalam ukuran yang berbedabeda. Oleh karena ia itu musuh maka perlulah ia dikuasai/ditaklukan agar supaya ia tidak menganggu lagi. Dalam Kakawin Ràmàyana sargah 1 disebutkan sebagai berikut ini :

Ragàdi musuh maparö, rihati ya tonggwanya tan madoh ring awak,

yeka tan hana ri sira, prawira wihikan sireng niti.

Terjemahannya :

Kesukaan, kegemaran dan lain-lain adalah musuh yang dekat, di hatilah tempatnya tidak jauh dari badan, yaitu tak ada pada beliau raja (Daúaratha), perwiran bijaksana dan pandai Beliau akan ilmu politik ( Poerbatjaraka,1982:3)
1) Kàma

Kama itu merupakan musuh didalam diri kita, selama ia itu tidak dikendalikan. Bila ia dapat dikendalikan ia akan menjadi sahabat kita yang baik. Karena adanya kama hidup kita ini kita rasakan penuh arti. Orang yang sudah bebas dari pengaruh kama adalah orang yang sudah banyak memenuhi tuntutan hidup ini. Ia sudah tahu gerak-gerik kama itu, karena ia sudah berkecimpung didalamnya. Dengan demikian orang yang dapat mengatasi kama itu ialah orang yang sudah lulus dalam banyak hal didalam hidup. Beberapa tahap-tahap kehidupan telah dilewatinya. Karena demikian perangilah kama itu, usahakanlah mengendalikannya.

\section{2) Lobha}

Lobha itu menyebabkan orang tidak puas akan sesuatu. Orang yang lobha itu selalu ingin memiliki lebih dari apa yang telah dimilikinya. Bila ia sudah memiliki apa yang ia ingini, inginlah ia menambah lagi. Untuk ia berpikir dan bekerja lebih keras lagi. Akibatnya orang yang demikian itu gelisah saja hatinya karena tergoda oleh kelobaannya. Ia tidak memiliki ketenangan hati, padahal setiap orang mengingini ketenangan hati, padahal setiap orang. Lobha itu adalah sifat semua orang. Lobha mendorong orang untuk berusaha, yang membawa kemajuan. Selama lobha itu didasari atas wiweka dan tri pramana ia adalah baik. Diluar itu akan membawa kehancuran. Ia adalah musuh yang harus selalu diawasi.

\section{3) Krodha}

Krodha atau marah tergolong soal perasaan. Orang yang suka marah itu tidak baik. Tidak ada seseorang yang senang dimarahi. Orang yang mendapat marah itu, akan marah pula, sehingga akan terjadilah hubungan yang buruk antara yang marah dengan yang dimarahi. Orang yang senang marah tidak disenangi oleh kawan-kawannya. Ia akan banyak mempunyai musuh. Bukankah kita ingin mempunyai sahabat sebanyak-banyaknya? Makin banyak mempunyai sahabat makin baik. Orang pemarah tidak banyak mempunyai sahabat. Dalam gaguritan pupuh Sinom disebutkan sebagai berikut :

Pidabdab sang kodag krodha, rikala ipun mamunyi, 
nenten ngetang salah beneh, tan ngetang larangan malih,

adharmane tan kimpasin, tur nyidayang ipun muwus,

sane tan sandang bawosang, bhuta

krodhane nyusupin,

dewek ipun, awinan mengawag-awag.

Terjemahannya:

Perilaku orang yang pemarah, ketika ia berkata tidak memperhatikan kata yang baik dan kata yang buruk, perbuatan yang adharma tidak dihindari, selalu ia berkata yang kasar, yang tidak boleh diucapkan, karena disusupi oleh kemarahan, pada dirinya oleh karena ia selalu berbuat jahat (Surada, 2006:237)

\section{4) Moha}

Moha atau kebingungan menyebabkan pikiranb itu gelap. Orang yang berada dalam kebingungan tidak dapat berpikir dengan baik dan tidak dapat pula bekerja sebagaimana mestinya. Karena pikiran itu bingung maka kesehatan badanpun akan menurun. Akibatnya tugas-tugaspun akan terbengkalai. Banyak hal yang menyebabkan orang menjadi bingung. Pada umunnya sebab-sebab itu ialah karena orang ditimpa kesusahan, yang hebat atau kehilangan sesuatu yang dicintainya. Dan tidak menemui jalan untuk mengatasinya. Agar supaya tidak ditimpa kebingungankebingungan yang hebat, maka kita perlulah setiap kita mengahadapi sesuatu diawali dengan pikiran yang tenang dan dapat mengirakan akibat pekerjaan itu. Dengan demikiankita sudah menyiapakan diri tidak akan bersedih sekali bila tidak berhasil dan tidak akan bergembira yang berlebih-lebihan bila tidak berhasil.

\section{5) $\mathrm{Mada}$}

Banyak orang mabuk karena minuman keras, minuman yang mengandung alcohol. Minuman yang demikian misalnya : arak, bier, tuak, berem, dll. Selama minuman itu diminum dalam batas-batas tertentu tidak akan membawa akibat yang buruk. Alkohol memberikan tenaga tetapi kalau ia berlebihan akan merusak tubuh. Ia melumpuhkan pencernaan dan merusak saraf. Karena orang itu yang saleh, yang mementingkan kesucian rohani tidak mau minum-minuman keras tab. Tetapi orang itu mabuk tidak hanya karena minuman keras .
Orang yang dapat pula mabuk, lupa diri, karena kekuasaan, kepandaian, atau kekayaan. Mabuk yang demikian lebih tercela daripada mabuk minuman. Ia tidak hanya merugikan diri sendiri, tetapi ikut merugikan orang lain, misalnya menyakiti hati orang lain, melanggar peri kemanusiaan dsb. Bila demikian halnya mabuk itu menjadi musuh. Tidak ada orang yang senang dengan yang mabuk-mabuk. Maka itu ia patut dijauhi.

6) Matsarya

Iri hati ialah perasaan tidak senang karena melihat orang lain lebih bahagia, lebih beruntung dsb. Daripada dirinya sendiri. Orang yang mempunyai rasa demikian itu merasa dirinya malang, miskin, buruk, dsb. Akibatnya akan timbullah perasaan-perasaan yang tidak baik terhadap orang yang beruntung itu, yang dapat menimbulkan pertengkaran, permusuhan, dsb.Hendaknya rasa iri hatiitu menggugah hati kita guna berusaha mengisi kekurangankekurangan diri sendiri sehingga hidup kita ini lebih sempurna. Dalam gaguritan pupuh Semarandana disebut sebagai berikut ini.

Janma sane irihati, maring gelah anak liyan,

doleg maring kasukhane, janmane kadi punika,

mangdoh pacang mangih suka, sekantun ipun idup, inggian maring para loka.

Terjemahannya:

Orang yang selalu memiliki pikiran irihati, kepada kepunyaan orang lain, dengki terhadap kebahagiaanya, orang yang seperti itu, pasti tidak mendapatkan kesenangan, selagi masih hidunya, demikian juga pada kehidupannya di akhirat nanti (Surada, 2006:268)

Iri terhadap orang lain tidaklah patut. Perasaan ini harus ditekan agar hubungan kita terhadap sesama kita baik, baik di Alam ini mapun di Akhirat nanti.

\subsection{Sapta Timira}

Sapta Timira artinya tujuh kegelapan. Yang dimaksud tujuh kegelapan ialah : tujuh hal yang sering menyebabkan pikiran orang menjadi gelap.Bila pikiran orang menjadi gelap, maka tingkah lakunya pun akan menyimpang dari tingkah laku yang dipandang orang benar dan baik. Sapta timira itu ialah : (1) Surupa; (2) Dhana; (3) Guna; (4) Kulina; (5) Yowana; (6) 
Sura; dan (7) Kacuran. Dalam gaguritan dengan pupuh Ginanti disebutkan sebagai berikut ini.

1. Sapta-timira kawuwus, Bacakan manahe paling,

Netan nyandang laksanayang, Magawe duhkita sai,

Wetuning irajah-tamah, Bacakannya siki-siki.

2. Kasuguhan ne pamucuk, Kapradnyanan kaping kalih,

Kayohanan kaping tiga, Ping pat kawangsa ne luwih,

Ping lima kalistuayuan, Ping nem kasaktian jati.

3. Kawiryan kaping pitu, Momon idep ngawe paling,

Ne sai nyandang tetehang, Bubhi satwa nggen nasarin,

Kasucian ne mautama, Pang sida mamangguh becik.

Terjemahannya :

1. Yang disebut Sapta Timira adalah pikiran yang bingung, tidak patut diikuti yang akan menyebabkan penderitaan, yang keluar dari pikiran yang agresip dan kemalasan, di uraikan satu persatu.

2. Kekayaan yang pertama, kepinteran yang kedua, keremajaan atau masa remaja yang ketiga, kalahiran yang keempat, kecantikan dan kebagusan yang kelima, kekuatan yang keenam.

3. Kewibawaan yang ketujuh, pikiran yang loba menyebabkan bingung, selalu patut dikendalikan, dilandasi oleh budhi yang lihur, yang paling utama adalah kesucian, supaya menjumpai kebaikan (Surada,2006:243)

\section{1) Surupa}

Surupa artinya kecantikan atau kebagusan. Kecantikan atau kebagusan adalah anugrah Tuhan yang dibawa sejak lahir. Orang yang memilikinya boleh merasa beruntung atas anugrah itu. Orang tidak boleh tekebur karena kecantikan atau kebagusannya karena sifatnya tidak kekal. Ketampanan jasmani haruslah disertai dengan keluhuran budi. Ketampanan jasmani yang tidak disertai dengan keluhuran budi tidak akan ada nilainya. Janganlah hendaknya surupa itu mengantar seseorang menuju kehancuran.

\section{2) Dhana}

Dhana artinya kekayaan. Kekayaan itu besar gunanya, namun besar pula godaannya. Setiap orang boleh mencari kekayaan, baik berupa kesenangan, asal tidak didapat dan diperguganakan untuk hal-hal yang tidak benar. Karena pengaruh kekayaan, orang sering jadi tekabur, menjadi sombong dan mengumbar hawa nafsunya, yang semuanya itu bertentangan dengan ajaran agama. Kekayaan itu lebih dihargainya daripada jiwanya sendiri. Untuk menghindari pengaruh yang demikian itu, setiap orang patut memiliki jalan pikiran yang sehat, yang tergoyahkan oleh pengaruhpengaruh yang buruk. Agama Hindu mewajibkan pemeluk-pemeliknya mempergunakan kekayaan itu untuk kesejahtraan hidup bersama. Patut pula setiap orang menginsapi bahwa kekayaan itu tidak kekal adanya. Orang akan tidak dikenang karena kekayaannya namun orang akan dikenang karena sifat baik atau buruknya yang akan mengantarkannya ke alam akhirat.

3) Guna

Guna artinya kepandaian. Setiap orang berusaha mencari kepandaian karena ia ingin menjadi orang yang pandai. Dengan kepandaian itu kita dapat memperingan hidup kita dan karena itu amat penting untuk hidup ini. Tetapi kepandaian itu berbahaya pula, bila tidak tahu mempergunakannya. Seringkali kepandaian itu dipergunakan orang untuk tujuan-tujuan yang buruk, misalnya untuk menipu, menghina, memperolok-olok orang lain, memperalat orang lemah dsb. Ada pula orang menjadi sombong, angkuh dsb. Karena memiliki suatu kepandaian dan mengira orang lain tidak tahu apa-apa. Demikianlah kepandaian itu akan membawa keburukan bilamana ia dimiliki oleh orang-orang yang berada dalam kegelapan rohani, orangorang yang batinnya tidak kuat/ tinggi. Kepandaian itu haruslah dipergunakan untuk keselamatan dan kebahagiaan bersama, kebahagiaan dan keselamatan diri sendiri dan orang lain.

4) Kulina

Kulina artinya kebangsawanan. Kebangsawanan itu diperoleh orang karena keturunan. Barangkali orang tuanya atau leluhurnya dahulu pernah berbuat jasa, sehingga ia di angkat menjadi bangasawan.Kebangsawanan lahir hendaknya disertai kebangsawanan budi. Ia tidak akan berharga bila orang itu tidak tahu membawa diri di dalam masyarakat, apalagi di orang 
jahat.Barang kali ada orang bangsawan menganggap orang - orang lain lebih hina, lebih rendah derajatnya, kurang berharga dan dapat diperlakukan lebih kasar daripada sesamanya. Tentu saja hal ini tidak benar, Karena tidak sesuai dengan peri kemanusiaan.

Kita adalah makhluk Tuhan yang dilahirkan sama dan mengharapkan perlakuan yang wajar dari orang lain. Betapa mengkalnya prasaan orang bila rasa harga dirinya tidak diperhatikan. Hendaklah orang tidak memperlakukan orang lain dengan perlakuan yang ia sendiri tidak senang bila diperlakukan demikian. Orang tidak boleh lupa diri sebagai makhluk social karena kebangsawanannya, ia memerlukan penghargaan dari orang lain dan karena itu ia harus menghargai dan memperhatikan orang lain seperti ia menghargai dirinya sendiri.

\section{5) Yowana}

Yowana artinya masa muda. Masa muda adalah masa gemilang, masa yang penuh masa kegairahan, masa banyak harapan. Orang muda badannya kuat, pikirannya cerdas. Ia adalah harapan masa depan orang tua, harapan nusa dan bangsa. Tetapi masa muda itu seringkalilah pula masa bimbang, karena tidak tahu akan kemanakah arah hidupnya kelak. Kadangkadang masa muda masa jiwa goyah, tidak ada keseimbangan. Maka untuk mencari keseimbangan itu, berbuatlah ia bermacammacam laku, yang seringkali hanya sekedar mengharap perhatian dan penghargaan orang lain. Dalam pada itu bermacam-macamlah tingkahnya yang seringkali melanggar kesopanan dan aturan - aturan kesusilaan sehingga merugikan orang lain.Janganlah hendaknya masa muda itu di sia - siakan demikian rupa; ia harus diisi dengan hal - hal yang baik, seperti menuntut ilmu, bekerja, rekreasi yang sehat dll.Guna bekal untuk berikutnya. Orang tidak boleh angkuh karena badan kuat. Kekuatan badan lama - lamaakan menurun. Maka itu budi baiklah hendaknya dipupuk. Dalam gaguritan pupuh Ginanti disebutkan sebagai berikut ini.

Kayohanan gede bayu, makejang anake ndogin,

tahu teken dewek bajang, anake tua cacadin,

tuara tau teken awak, masih lakar tua buin.
Terjemahannya:

Menjadi remaja dengan pisik yang kuat, semua orang yang mau dilawan, karena tahu dengan diri yang remaja dan kuat, senang mengejek orang tua, karena tidak tahu dengan diri, bahwa suatu saat akan menjadi tua dengan pisik yang lemah (Surada,2006:244)

6) Sura

Sura artinya minuman keras. Minuman ini misalnya : tuak,arak, bier, dll.Semuanya memabukkan bila tak tahu meminumnya. Ini berarti merusakkan jasmani yang di susul oleh kerusakan rohani. Sekarang ada pula sejenis barang perangsang yang ajaib yang membawa akibat sejenis minuman keras ini, namun jauh lebih hebat dan lebih jahat. Barang perangsng ini ialah : candu, gajah, heroin, dsb. Siapa yang pernah mencoba meminumnya, ketagihanlah ia untuk selanjutnya. Kemudian lumpuhlah sarafnya dan jiwanya menjadi rusak. Janganlah mencoba - coba minum benda - benda ini, minumlah apa-apa yang menyehatkan tubuh.

7) Kasuran

Kacuran artinya keberanian. Keberanian itu perlu dimiliki oleh setiap orang, seperti keberanian berjuang, keberanian mempertahankan kebenaran dll. Tidak semua orang memiliki keberanian yang cukup, banyak yang pengecut.

Tidaklah boleh orang mabuk keberanian, karena keberanian bukan semata - mata untuk bermabuk - mbukan. Keberanian adalah untuk membela yang patut dibela. Dalam Nitisara. sargah IV. 19 disebutkan sebagai berikut ini.

Lwirning manadadi madaning jana surupa dhana kula-kulina yowana,

Lawan tang sura lan kacuran agawe wereh di manah ikang sarat kabeh, Yan wanten sira sang dhanecwara surupa guna dhana kulina yowana,

Yan tan mada mahardhikeka pangaranya sira putusi sang pinandita.

Terjemahannya :

Yang bisa membikin mabuk, ialah keindahan, harta benda, darah bangsawan dan umur muda. Juga minuman keras dan keberanian bisa membikin mabuk hati manusia. Jika ada orang kaya,indah rupanya, pandai,banyak harta bendanya, berdarah bangsawan lagi muda umurnya, 
dan karena semua itu ia tidak mabuk, ia adalah orang yang utama, bijaksana tak ada bandingnya.

\subsection{Daivi Sampat dan Asuri Sampat}

Dalam Bhagavadgita kecendrungankecendrungan sifat manusia dibedakan menjadi dua bagian yaitu : (1) Daivi Sampat, yaitu kecendrungan kedewataan. Kecendrungan kedewataan adalah kecendrungan - kecendrungan yang mulia yang menyebabkan manusia berbudi luhur yang mengantarkan orang untuk mendapatkan kerahayuan; (2) Asuri Sampat, yaitu kecendrungan keraksasaan. Kecendrungan ini adalah kecendrungan yang rendah yang menyebabkan manusia dapat jatuh kejurang naraka. Kedua kecendrungan itu ada pada diri semua orang hanya dalam ukuran yang berbeda-beda . Ini berarti bahwa dalam diri manusia terdapat sifat baik dan sifat buruk.

Sarasamuscaya menyebutkan bahwa hanya manusialah yang mengenal perbuatan yang salah dan benar baik dan buruk. Dan dapat menjadikan yang tidak baik itu menjadi baik. Itulah salah satu kemampuan manusia yang diberikan oleh Sang Hyang Widhi.

\section{III.PENUTUP}

Apabila kita berbicara tentang pengendalian diri yang terwujud dalam bentuk etika, maka kita harus memperhatikan faktor-faktor lain yang menunjang demi dapatnya orang mengendalikan dirinya itu. Biarpun bagaimanapun bagusnya teori pengendalian diri itu dan kuatnya pribadi seseorang, bila faktor-faktor penunjang untuk itu lemah, sulit juga orang dapat mengendalikan diri dalam bentuk etika dengan baik. Seseorang yang ingin mengendalikan pikirannya dan beretika, mengabaikan aspek-aspek kemanusiaan lainnya, maka ia tidak akan mendapatkan hasil yang diharapkan. Sebagaimana halnya seorang guru yang mengajarkan ajaran pengendalian diri dan etika yang hanya memandang manusia dari segi etika saja, ia juga tidak mendapatkan hasil. Manusia terdiri dari dua unsur yaitu unsur jasmani dan rohani . Antara jasmani dan rohani terdapat hubungan yang sangat erat. Perubahan pada jasmani berpengaruh pada kejiwaan seseorang, demikian pula sebaliknya.

Dari uraian tersebut di atas, ternyata bahwa aspek-aspek kehidupan manusia itu meliputi aspek kerohanian dan aspek kejasmanian. Dari integrasinya dalam kehidupan bersama ini menjadi tidak bebas, karena harus tunduk pada norma-norma dan aturanaturan yang berlaku dalam masyarakat sebagai makhluk sosial. Dalam pada itu iapun harus menghadapi dirinya sendiri, sebagai individu yang harus dapat dikuasainya. Dengan demikian ia harus berjuang dalam mempertahankan eksistensi hidupnya . Ia harus berjuang terhadap lingkunagnnya sendiri dan dengan dirinya sendiri. Karena itu hidup ini adalah suatu persoalan yang harusselalu dihadapi dan diselesaikan setiap hari.

Ajaran Agama Hindu selalu memberi saran agar orang selalu mengarahkan hidupnya dengan berbagai persoalannya itu menuju kebahagiaan melelui jalan yang baik dan benar. Untuk itu ia harus dapat menguasai dirinya sendiri sehingga dalam penempilannya dengan orang lain merupakan penempilan yang baik dan membahagiakan semua orang. Beberapat ajaran tersebut adalah: ajaran Trikaya Parisudha, ajaran Sad Ripu, ajaran Sapta Timira dan dua kecendrungan pada diri manusia yaitu kecendrungan yang baik dan kecendrungan yang buruk yang selalu bergulat dalam dirinya.

\section{DAFTAR PUSTAKA}

Cudamani, 1987. Pengantar Agama Hindu Untuk Perguruan Tinggi. Jakarta: Yayasan Wisma Karma.

Kajeng, 1999. Sarasamuscaya. Surabaya: Paramita. Pudja, 1999. Bhagavagita. Surabaya : Paramita.

Purbatjaraka, 1982. “Arti Ràmàyana” Denpasar: Institut Hindu Dharma Denpasar.

Sura,1985. Pengendalian Diri dan Etika Dalam Ajaran Agama Hindu. Jakarta: Hanuman Sakti.

1991. Agama Hindu Sebuah Pengantar. Denpasar : CV Kayumas Agung.

1999. "Siwatattwa". Denpasar: Pemerintah Daerah Tingkat I Bali PPPPKB.

Surada, 2006. Dharmagita Kidung Pañca Yajña, Beberapa Wirama, Úloka, Phalawakya dan Macepat. Surabaya: Paramita 